\title{
A PROPOSED CASE STUDY FIELD RESEARCH METHODOLOGY TO TEST COST DRIVERS: AN EXAMPLE OF PROPOSED FIELD STUDY AT A NUCLEAR MEDICINE UNIT
}

\author{
Dr. Min (Shirley) Liu \\ Assistant Professor \\ Department of Accounting \\ Brooklyn College-CUNY Brooklyn, New York, United States \\ E-mail: min.liu@brooklyn.cuny.edu
}

\begin{abstract}
This paper illustrates how to use case study method to conduct the cost driver research at hospitals by identifying activity-based cost drivers at the nuclear medicine unit (NMU) of a teaching hospital. I argue that recognizing the activity-based cost could improve the accuracy of estimating costs by identifying the underutilized resources and value-added and non-value-added cost drivers, to reduce non-value-added costs; thereby, facilitating the management to make better informed managerial decisions (e.g., improving pricing practices and using resources more efficiently). Therefore, I believe that this study may provide a useful inference to hospitals to improve the quality and quantity of the service, which they (or would) provide. Furthermore, this paper possibly provides an informative research methodology for researchers by showing how to extend the current literature by applying the same cost analysis research model on a different dataset for the health care industry research.
\end{abstract}

Keywords: Cost Driver, Hospitals, Pricing Service.

JEL Classification Codes: M10, M11, M40, M41.

\section{INTRODUCTION}

Increasing worldwide competition invokes an immense effort to manage costs. The theme that there is a necessity to control costs throughout the health care field has received a great deal of attention from academic professionals and regulators since early this century. However, because of the unique characteristics of the health care industry and the difficulties to access the informative database, there is a very limited amount of research that has been done in this area. This paper proposes to find an accurate method to identify the factors that cause or drive the costs at a teaching hospital. The identification of cost drivers enables more efficient management of national resources devoted to health care practice, thereby, possibly benefiting all health care stakeholders.

The regulations in health care industry increase the complexity of cost analysis for hospitals. For example, according to Cleverley (1992), the revenue earning departments provide inpatient routine services (e.g., nursing and accommodation), ancillary services (e.g., operating room and physical therapy), outpatient services (e.g., emergency care) and/or other services (e.g., ambulance services). These departments directly charge patients or indirectly charge the third-party payers, for the services which they provided. The nonrevenue earning departments provide general 
services such as cafeteria and housekeeping, the costs of which are overhead costs and assigned to the revenue earning departments. Although market forces and government regulations allow that these overhead costs are recovered as part of the amounts billed by the revenue earning departments (MacArthur \& Stranahan, 1998), it is important for the administrators of health care entities to have accurate cost information. West, Balas, \& West (1996) indicate that health care managers who have more accurate cost information could make more effective decisions on resource allocation, cost containment, and incentives that drive the selection of treatment alternatives. Moreover, these more accurate cost estimations facilitate a more effective planning and a control method for hospitals. This study proposes to use the field study method to identify the activity-based cost drivers in the nuclear medicine unit (NMU) at a teaching hospital, to provide an accurate method to estimate costs in hospitals and enable hospitals to reduce nonvalue added cost given that the level of output (the quality of medical service) is not change.

The rest of this paper is organized as follows. The next section introduces the literature relevant to this paper. Section 3 develops the cross-sectional cost regression model. Section 4 proposes the data and method used. The last section concludes.

\section{LITERATURE REVIEW}

This paper is related to the previous studies mainly along the following two streams.

The first steam are studies on general cost driver. The research on cost driver analysis (e.g., Miller \& Vollman, 1985; Cooper \& Kaplan, 1987) suggests that, in addition to output volume, overhead cost can be driven by transactions deriving from the diversity of a firm's product line and the complexity of its production process. Consequently, more cost drivers (e.g., cost drivers related to operating activities) should be considered in addition to the traditional cost measures based only on volume-related measures (e.g., direct labor hours, units of output, or machine hours). Some firms have designed and implemented activity-based accounting systems (Schiff 1991). Later, a number of research (e.g., Anderson, 1995; Balakrishnan, Gruca, \& Nath, 1996; Banker \& Johnson, 1993; Banker, Potter, \& Schroeder, 1995; Foster \& Gupta, 1990) have focused on determinants of operating cost. Foster and Gupta (1990) and Banker et al. (1995) tested the simple assertion that magnitude of batch and other non-volume-level drivers affect overhead cost. Few papers have investigated the less obvious proposition that complexity of operations (Cooper \& Kaplan, 1987) and the level of congestion in the system (Banker, Datar, \& Kekre, 1988) also affect the cost of operations. However, these studies did not examine the cost driver in the health care industry.

The second stream of previous literature related to this paper is that of the studies on the hospital cost driver. The identification of cost drivers may enable more efficient management of the national resources devoted to health care, thereby, benefiting the health care stakeholders. More accurate allocation of hospital costs using appropriate cost drivers could make cost data more reliable for purposes of pricing and others (such as finding individual hospital's own cost parameters).

Moreover, the supply of cost information may help hospital managers determine the profitability vs. outsourcing diagnostic tests (Lawson, 2005) and monitor cost related to nonvalueadded activities (e.g., patient waiting time). Research suggests that identifying overhead or indirect cost drivers is very useful in the health care industry (e.g., Rotch, 1990; Helmi, \& Tanju, 1991; Young \& Pearlman, 1993; Lawson, 2005). MacArthur and Stranahan (1998) investigate the significance of volume and complexity variables in determining hospital overhead costs, and how these variables are structurally related and the way to estimate the cost impacts of these variables 
in practice. MacArthur and Stranahan (1998) use simultaneous equations to estimate the level of general services (overhead) costs needed to support the service provided. They find that volume and complexity (e.g., number of medical services and depth of ancillary services) are significant drivers of hospital costs.

Furthermore, research findings support the adoption of activity-based costing (hereafter ABC) in health care industry (e.g., Chan, 1993; Cokins, 1996; Dowless, 1997; West \& West, 1997). For example, Chan (1993) argues that ABC could be applied in the health care sector in which procedures/patients are unique products themselves. Chan (1993) suggests that ABC provides more accurate cost information than do conventional costing systems for health care industries.

Although the aforementioned studies suggest that cost analyses could apply in the health care industry, none of these studies examines the cost drivers at department/unit level of a hospital. The cost analysis for each department is heterogeneous in a hospital. Each department operates in a unique way. Therefore, it is very important for management of a hospital to have accurate cost information at department level. Thus, this paper will partially fill this gap. Suthummannon, Vincent, and Mehmet (2005) propose the application of ABC to the nuclear medicine unit (NMU) of a teaching hospital. However, in that paper, the authors do not provide the systematic estimation model to analyze the cost drivers in NMU. This study extends Suthummannon et al. (2005), by providing a systematic statistical model to identify the activity-based cost drivers in the NMU and by using a different research site. In other words, this study contributes the current existing relevant research by proposing to use a different analytical model and a different dataset.

\section{HYPOTHESIS DEVELOPMENT \& EMPIRICAL MODELS}

I choose the NMU as a research site because there is a big proportion of its costs represent represented by variable costs which can be controlled and reduced. ${ }^{1}$ Therefore, there is a good opportunity for managing the total cost of the procedure. I propose to use cross-sectional data to examine cost drivers in NMU in a teaching hospital for the research purpose of this study (i.e., finding out what are the cost drivers). The essential benefit of cross-sectional data is to catch the variation in costs caused by various activities, while this benefit might not be reflected in a timeseries study of a plant. ${ }^{2}$ Therefore, using cross-sectional analysis is more suitable for this study than using time-series analysis.

I propose to use nuclear medicine as a field study site is to simplify my cost analysis and to find parameters of the models because it has a relatively clear picture to show the identification of cost drivers. Nuclear medicine is a specialized area of radiology that uses very small amounts of radiology materials or radiopharmaceuticals to examine organ function and structure. Scans are used to diagnose many medical conditions and diseases. A nuclear medicine scan contains three stages: tracer (radiopharmaceutical) administration, taking images, and image interpretation. The length of time between the administration of the tracer and the taking of the image may range from a few minutes to a few days, depending on the body tissue being examined and the tracer being used. In addition, the time needed to obtain the images might also vary from only a few minutes to several hours.

\footnotetext{
${ }^{1}$ In the research site adopted by Suthummannon et al. (2005), over $85 \%$ of NMU costs are the variable costs that can be reduced.

${ }^{2}$ Banker et al. (1995) mentioned the benefit of using cross-sectional data to examine cost drivers in different plants. However, the reason for employing the cross-sectional data instead of time-series data is the same. Time-series data would bring too much noise affecting the analysis, such as the effects of microeconomic environment and governmental regulations. The latter affects the costs of a hospital greatly because of the quick adjustment of regulations in this industry.
} 
There are several different procedures performed in the NMU. Each procedure requires a specific set-up of machine and equipment, which are maintained by the maintenance department of the hospital. After the machine is set up, the radiologist uses the materials and supplies delivered by the supply processing and distribution department to perform the procedures. As the procedures are performed, the clerks will complete the required documents and distribute the results to the appropriate party. The labor source is very important in each step per procedure, as Cokins (1996) states that health-care institutions are labor-intensive industry where work activities represent most of their costs. following:

Summarizing the discussion above, the first hypothesis is stated in the alternative form as

\section{$H_{1}:$ The director labor hours would be the most influential cost driver at the NMU.}

The longer the machine has been used in procedures, the more likely the machine needs more maintenance or/and be replaced earlier than those have not been used so intensively. Therefore, the second hypothesis stated in alternative form as following:

\section{H2: The hours that the machine has been used would be a cost driver at the NMU.}

Similarly, the more procedure was undertaken, the higher cost would be. The third hypothesis stated in the alternative form is as following:

\section{$H_{3}:$ The number of procedures would be a cost driver at the NMU.} cost drivers.

The following table shows the hypothetical relationship between costs and activity-based

\begin{tabular}{|l|l|l|}
\hline \multicolumn{2}{|l|}{ Cost Drivers by Activity } \\
\hline Activity cost pool (measurement US\$/Year) & Activity cost driver & Hypothesized sign \\
\hline Administration & Direct Labor & $(+)$ \\
\hline Office supplies & No. of procedures & $(+)$ \\
\hline Purchased service & Direct Labor & $(+)$ \\
\hline Data processing & No. of procedures & $(+)$ \\
\hline Repairs and maintenance & Machine Hours & $(+)$ \\
\hline Service contracts & Direct Labor & $(+)$ \\
\hline Professional fees & Direct Labor & $(+)$ \\
\hline Radiation control & Direct Labor & $(+)$ \\
\hline Replacement/monitor equipment & Machine Hours & $(+)$ \\
\hline Employee training & Direct Labor & $(+)$ \\
\hline
\end{tabular}


The empirical model is described by the following system of equations to test hypotheses:

Administration: $\mathrm{y}_{1}=\alpha_{1}+\beta_{1} \mathrm{DL}+\mathrm{e}_{1}$,

Office supplies: $\mathrm{y}_{2}=\alpha_{2}+\beta_{2} \mathrm{NP}+\mathrm{e}_{2}$,

Purchased service: $\mathrm{y}_{3}=\alpha_{3}+\beta_{3} \mathrm{DL}+\mathrm{e}_{3}$,

Data processing: $\mathrm{y}_{4}=\alpha_{4}+\beta_{4} \mathrm{NP}+\mathrm{e}_{4}$,

Repairs and maintenance: $\mathrm{y}_{5}=\alpha_{5}+\beta_{5} \mathrm{MH}+\mathrm{e}_{5}$,

Service contracts: $\mathrm{y}_{6}=\alpha_{6}+\beta_{6} \mathrm{DL}+\mathrm{e}_{6}$,

Professional fees: $\mathrm{y}_{7}=\alpha_{7}+\beta_{7} \mathrm{DL}+\mathrm{e}_{7}$,

Radiation control: $\mathrm{y}_{8}=\alpha_{8}+\beta_{8} \mathrm{DL}+\mathrm{e}_{8}$,

Replacement/minor equipment: $\mathrm{y}_{9}=\alpha_{9}+\beta_{9} \mathrm{MH}+\mathrm{e}_{9}$,

Employee training: $\mathrm{y}_{10}=\alpha_{10}+\beta_{10} \mathrm{DL}+\mathrm{e}_{10}$,

Where,

$\mathrm{y}_{1}, \mathrm{y}_{2}, \ldots, \mathrm{y}_{10}=$ expenses measured by the U.S. dollar amount during the fiscal year 2005,

DL=Direct labor hours measured by hour during the fiscal year 2005,

$\mathrm{NP}=$ No. of procedures during the fiscal year 2005,

$\mathrm{MH}=$ Machine hours measured by hour during the fiscal year 2005,

If a coefficient of the estimate is positive and statistically significant in the system equation, the corresponding independent variable will be considered as the cost driver in the NMU of the hospital.

\section{SAMPLE AND DATA SELECTION}

The research site used in this research is the nuclear medicine unit of a teaching hospital, which is a hypothetical site to illustrate how to conduct such kind of field study. The reason for choosing the nuclear medicine unit is because it has a higher possibility of improving cost management than do other departments (this unit has a large proportion of variable costs). All financial data are provided by the hospital for the fiscal year $2005 .^{3}$

The model will be tested using econometrical regression analysis and the statistical analysis

\footnotetext{
${ }^{3}$ This paper attempts to show how to conduct a cost analysis research at a teaching hospital, which is a hypothetical research site and the fiscal year 2005 is also a hypothetical fiscal year. Interested researchers could modify their selection on hypothetical research site and data range suitable for their research purposes and utilization of available data.
} 
of data could be performed using SAS or any other statistical software package that researchers prefer to use (e.g., STATA, SPSS, MATLAB, R...).

\section{DISCUSSION AND FUTURE RESEARH PERSPECTIVE}

This study is just to illustrate how to set up a simple cost analysis at a unit of hospital and therefore may be subjected to some limitations. It is very difficult to identify all cost drivers; there is a possibility of omitting variable error. More complex model might be better to identify more accurate effects of the cost drivers on the cost.

There are a lot of open issues in the of cost control in health care industry. For example, there is much debate regarding what kind of health provider organization is preferential for the entire society (e.g., preferred provider organization [PPO] or health maintenance organization [HMO]). Future research may examine which health provider organization might achieve the maximum utility, in other words, the highest output at a certain input level. The relationship between the ownership structure (i.e., for profit or non-for-profit) and the cost of the hospital might also be a good research topic.

\section{ACKNOWLEDGEMENTS}

I thank Indrarini Laksmana, Fangjun Sang, participants of the session of Effect of Strategy Map on Decisions and Cost Drivers on Nuclear Medicine at the AAA 2021 Spark: Meeting of the Regions, and anonymous referees for their helpful comments on this paper.

\section{REFERENCES}

Anderson, S. (1995). Measuring the Impact of Product Mix Heterogeneity on Manufacturing Overhead Cost. The Accounting Review, 70(3), 363-388.

Balakrishnan, R. T., Gruca, T., \& Nath, D. (1996). The Effect of Service Capability on Operating Costs: An Empirical Study of Ontario Hospitals. Contemporary Accounting Research, 13(1), 177-206.

Banker, R. D., Datar, S.M., \& Kekre, S. (1988). Is Assigning Capacity Costs to Products Really Necessary for Capacity Planning? Accounting Horizons, 10(4), 1-11.

Banker, R.D., \& Johnston, H. H. (1993). An Empirical Study of Cost Drivers in the U.S. Airline Industry. The Accounting Review, 68(3), 576-601.

Banker, R.D., Potter, G., \& Schroeder, R. (1995). An Empirical Analysis of Manufacturing Overhead Cost Drivers. Journal of Accounting and Economics, 19(1), 115-137.

Chan, Y.L. (1993). Improving Hospital Cost Accounting with Activity-based Costing. Health Care Manage Review, 18(1), 71-8.

Cleverley, W.O. (1992). Essentials of health care finance (3rd ed). Gaithersburg, MD: Aspen Publishers, Inc.

Cokins, G. (1996). Activity-Based Cost Management: Making it Work - A Manager's Guide to Implementing and Sustaining an Effective ABC System. Irwin Publishing: Chicago. 
Cooper, R., \& Kaplan, R.S. (1987). How Cost Accounting Systematically Distorts Costs. In Accounting and Management: Field Study Perspectives, edited by W.J. Bruns, and R. Kaplan. Boston, MA: Harvard Business School Press.

Dowless, R.M. (1997). Using Activity-based Costing to Guide Strategic Decision Making. Healthcare Financial Manage, 51(6), 86-89.

Foster, G., \& Gupta, M. (1990). Manufacturing Overhead Cost Driver Analysis. Journal of Accounting and Economics, 12(1-3), 309-337.

Helmi, M. A, \& Tanju, M. N. (1991). Activity-based Costing May Reduce Costs, Aid Planning. Healthcare Financial Management. Journal of the Healthcare Financial Management Association, 45(11), 95-96.

Lawson, R.A. (2005). The Use of Activity Based Costing in the Healthcare Industry: 1994 vs. 2004. Research in Healthcare Financial Management, 10(1), 77-94.

MacArthur, J. B., \& Stranahan, H.A. (1998). Cost Driver Analysis in Hospital: A Simultaneous Equations Approach. Journal of Management Accounting Research 10, 279-312.

Miller, J.G., \& Vollmann, T.E. (1985, September). The Hidden Factory. Harvard Business Review.

Rotch, W. (1990) Activity Based Costing in Service Industries. Journal of Cost Management, 4(2), 4-14.

Schiff, J.B. (1991). Cost Management Updated. National Association of Accountants. (January): $1-2$.

Suthummanon, S., Vincent, O.K., \& Mehmet, A. (2005). Applying Activity-based Costing to the Nuclear Medicine Unit. Health Services Management Research, 18(3), 141-150.

West, D.A., West, T.D. (1997). Applying ABC to Healthcare. Manage Account, 78(8), 22-32.

West, D.A., Balas, A.E., \& West, T.D. (1996). Contrasting RCC, RVU and ABC for Managed Care Decisions. Healthcare Financial Manage, 50(8), 54-62.

Young, D. W., \& Pearlman. L.K. (1993, April). Managing the Stages of Hospital Cost Accounting. Healthcare Financial Management, 47(4), 58-80.

\section{Copyrights}

Copyright for this article is retained by the author(s), with first publication rights granted to the journal. This is an open-access article distributed under the terms and conditions of the Creative Commons Attribution license (http://creativecommons.org/licenses/by/4.0). 